\title{
Plasmin and Plasminogen Activator Inhibitor Type 1 Promote Cellular Motility by Regulating the Interaction between the Urokinase Receptor and Vitronectin
}

\author{
David A. Waltz, ${ }^{\star \ddagger}$ Lisa R. Natkin, ${ }^{\ddagger}$ Ross M. Fujita, ${ }^{\ddagger}$ Ying Wei, ${ }^{\ddagger}$ and Harold A. Chapman ${ }^{\ddagger}$ \\ $*$ Division of Respiratory Diseases, Children’s Hospital, ${ }^{\ddagger}$ Respiratory Division, Brigham and Women’s Hospital, and ${ }^{* \ddagger}$ Harvard Medical \\ School, Boston, Massachusetts 02115
}

\begin{abstract}
The urokinase receptor (UPAR) coordinates plasmin-mediated cell-surface proteolysis and promotes cellular adhesion via a binding site for vitronectin on UPAR. Because vitronectin also binds plasminogen activator inhibitor type 1 (PAI-1), and plasmin cleavage of vitronectin reduces PAI-1 binding, we explored the effects of plasmin and PAI-1 on the interaction between UPAR and vitronectin. PAI-1 blocked cellular binding of and adhesion to vitronectin by over $80 \%\left(\mathrm{IC}_{50}\right.$ $\sim 5 \mathrm{nM}$ ), promoted detachment of uPAR-bearing cells from vitronectin, and increased cellular migration on vitronectin. Limited cleavage of vitronectin by plasmin also abolished cellular binding and adhesion and induced cellular detachment. A series of peptides surrounding a plasmin cleavage site (arginine 361) near the carboxy-terminal end of vitronectin were synthesized. Two peptides spanning res 364380 blocked binding of $\mathrm{UPAR}$ to vitronectin $\left(\mathrm{IC}_{50} \sim 8-25 \mu \mathrm{M}\right)$ identifying this region as an important site of uPAR-vitronectin interaction. These data illuminate a complex regulatory scheme for uPAR-dependent cellular adhesion to vitronectin: Active urokinase promotes adhesion and also subsequent detachment through activation of plasmin or complex formation with PAI-1. Excess PAI-1 may also promote migration by blocking cellular adhesion and/or promoting detachment, possibly accounting in part for the strong correlation between PAI-1 expression and tumor cell metastasis. ( $J$. Clin. Invest. 1997. 100:58-67.) Key words: cancer • cell migration • fibrinolysis • metastasis • monocyte
\end{abstract}

\section{Introduction}

Generation of pericellular plasmin by urokinase (uPA), ${ }^{1}$ with subsequent direct or indirect proteolysis of the extracellular matrix, is felt to be an important component in matrix remodeling and cellular migration (1). This paradigm has recently

Portions of this work have been previously published in abstract form (Chapman, H.A., D.A. Waltz, Y. Wei, and N. Rao. 1995. The Paulo Foundation Symposium 5th International Workshop on Molecular and Cellular Biology of Plasminogen Activation. 39; and Waltz, D.A., L.R. Natkin, Y. Wei, and H.A. Chapman. 1996. Am. J. Respir. Crit. Care Med. 153:A670)

Address correspondence to David A. Waltz, M.D., Children's Hospital, 300 Longwood Ave., Boston, MA 02115. Phone: 617-3556105; FAX: 617-355-6109; E-mail: waltz@a1.tch.harvard.edu

Received for publication 31 October 1996 and accepted in revised form 4 April 1997.

J. Clin. Invest.

(C) The American Society for Clinical Investigation, Inc. 0021-9738/97/07/0058/10 \$2.00

Volume 100, Number 1, July 1997, 58-67 been verified by analysis of plasminogen-deficient mice, which exhibit delayed wound healing (2). As the urokinase/plasmin system appears to be intricately involved in inflammation, wound repair, angiogenesis, and tumor development (1-4), regulation of these proteases has been extensively studied. The local tissue levels of active urokinase and plasmin are regulated by plasminogen activator inhibitor types 1 and 2 (PAI-1 and PAI-2) as well as by surface receptors for the proteases (5). Plasminogen/plasmin binds to specific cell surface receptors, and once bound is protected from the major plasmin inhibitor, $\alpha$-2-antiplasmin (6). Active two-chain urokinase and its single chain pro-enzyme form (pro-uPA) avidly bind to specific glycosylphosphatidylinositol (GPI)-anchored cell surface receptors (UPAR), also promoting focused pericellular proteolysis $(7,8)$. Although urokinase bound to $\mathrm{UPAR}$ is relatively stable on the cell surface, inhibition of active urokinase by complex formation with PAI-1 or PAI-2 results in rapid removal of urokinase/PAI/uPAR complexes from the cell surface, degradation of urokinase/PAI, and recycling of uPAR (4). Thus occupation of cell surface uPAR by uPA and concomitant urokinase activity are transient in the setting of these protease inhibitors. Expression of these elements of the plasminogen activator system, urokinase, uPAR, and especially PAI-1, are upregulated during inflammatory $(9,10)$ and malignant (11) processes. The net effect of competing interactions among these components of the urokinase/plasmin system, as they determine pericellular plasmin generation, regulates extravascular fibrin turnover.

In addition to binding urokinase, uPAR is a multifunctional protein implicated in cellular adhesion $(12,13)$, migration $(14,15)$, and signaling (16). We have previously documented a nonproteolytic role for $\mathrm{UPAR}$ as a cellular adhesion receptor for the matrixlike form of vitronectin $(17,18)$. uPAR contains a vitronectin binding site(s) distinct from the urokinase binding site and the strength of interaction between $\mathrm{uPAR}$ and vitronectin is proportional to concurrent $\mathrm{UPAR}$ receptor occupancy by uPA. This phenomenon is not dependent upon proteolytic activity as relatively inactive pro-uPA, twochain active UPA, and fragments of the UPA molecule containing only the amino-terminal uPAR-binding domain all promote uPAR/vitronectin binding $(17,18)$. More recently, we have demonstrated that the capacity of UPAR to act as an adhesion receptor depends as well on a functional and physical association with integrins (19). uPAR forms complexes with

1. Abbreviations used in this paper: ATF, amino-terminal fragment of urokinase; caPAI-1, recombinant constitutively active PAI-1; DFP, diisopropylfluorophosphate; $\mathrm{D}_{3}, 1,25-(\mathrm{OH})_{2}$-vitamin $\mathrm{D}_{3}$; FBN, fibronectin; PAI, plasminogen activator inhibitor; pro-uPA, single chain urokinase; RGD, arginine-glycine-asparginine; SMB, somatomedin B domain of vitronectin; suPAR, biotinylated soluble recombinant urokinase receptor; uPA, urokinase-type plasminogen activator; uPAR, urokinase receptor, VTN, vitronectin. 
activated integrins, presumably utilizing integrin connections to the cytoskeleton to promote stable adhesion to vitronectin mediated by the distinct binding site on uPAR. Thus uPAR changes the adhesive behavior of integrins. This association between integrins and UPAR may underly in part previous reports demonstrating a direct role for UPAR in cellular migration $(14,15)$, cellular signaling (16), and transmembrane force transduction (20). Moreover, because vitronectin is also the major high-affinity PAI-1 binding protein in both blood and tissues $(21,22)$, these observations directly link the adhesive properties of uPAR-expressing cells with regulation of a proteolytic cascade known to promote migration.

Cellular migration requires adhesion to the underlying cellular or extracellular matrix (23). This adhesion may not be so stringent as to prevent movement nor too weak to provide traction. The extent of migration may thus vary with the avidity of adhesion (24). In addition, adhesion must be regulatable or reversible to allow detachment. Detachment from focal adhesive sites during migration is thought to occur by several mechanisms including cell surface proteolysis, alterations in integrin conformation, and bulk shedding of attachment sites $(23,25)$. As uPAR has been implicated in cellular migration, regulates integrin function, and directly interacts with vitronectin, a matrix component prominent at sites of inflammation (10, 26-28), we have explored whether regulatory components of the urokinase/plasmin system also directly modify the adhesive potential of UPAR. As we and subsequently others (29) have recently reported, PAI-1 blocks binding of and adhesion to vitronectin by cytokine-stimulated myeloid cells and also blocks binding of soluble uPAR (suPAR) to vitronectin. While this study was in progress Kanse et al. demonstrated that PAI-1 blocks binding of vitronectin to UPAR on endothelial cells (30). We extend these observations by demonstrating that PAI-1 can directly affect migration of uPAR-expressing cells on vitronectin. Further, we show that cleavage of vitronectin by plasmin can reduce uPAR-dependent adhesion. Finally, while it has been suggested that UPAR binds to the amino-terminal somatomedin B domain (SMB) of vitronectin (29), we now present data implicating the heparin-binding domain located at the carboxy end of vitronectin in UPAR binding. These findings shed light on the increasingly complex role of the plasminogen activator system in the regulation of cellular motility and migration.

\section{Methods}

Reagents. RPMI 1640 and DME were obtained from Mediatech (Herndon, VA), FBS was from Hyclone Laboratories (Logan, UT), and penicillin, streptomycin, and Hepes were from Gibco BRL (Gaithersburg, MD). TGF- $\beta_{1}$ was obtained from Collaborative Research (Bedford, MA) and plasmin from American Diagnostica (Greenwich, CT). Drs. Robert J. Drummond and Steven Rosenberg (Chiron Corporation, Emeryville, CA) kindly donated biotinylated recombinant suPAR, Dr. David Ginsburg (University of Michigan, Ann Arbor, MI) supplied PAI-1 cDNA, Dr. Jack Henkin (Abbott Laboratories, Abbott Park, IL) provided recombinant two-chain high molecular weight uPA, single-chain uPA (pro-uPA), and an aminoterminal fragment of uPA (ATF), and Dr. M. Uskokvic (HoffmannLaRoche Laboratories, Nutley, NJ) furnished 1,25-(OH $)_{2}$ vitamin $\mathrm{D}_{3}$ $\left(\mathrm{D}_{3}\right)$. Two-chain uPA was inactivated by incubation with diisopropylfluorophosphate (DFP-uPA) as described (13). Recombinant human PAI-1, over $75 \%$ active based on binding of tissue plasminogen activator (31), was the kind gift of Dr. Thomas Reilly (DuPont-Merck,
Wilmington, DE). Recombinant constitutively active PAI-1 (caPAI-1) was obtained from Molecular Innovations, Inc. (Royal Oak, MI). Synthetic peptides corresponding to vitronectin residues 347-356 (VN-1, TKKQRFRHRN), 357-366 (VN-2, RKGYRSQRGH), 371-380 (VN-3, NQNSRRPSRA), and 364-375 (VN-4, RGHSRGRNQNSR) were obtained from commercial sources (Tana Laboratories, LC., Houston, TX and Quality Controlled Biochemicals, Inc., Hopkinton, MA) and diluted in PBS $/ 0.2 \%$ BSA. Two additional peptides, SC-3 (SNRPQARSRN) and SC-4 (NRQRGSNRSRGH), representing randomly scrambled sequences of peptides VN-3 and VN-4, respectively, were similarly prepared. All other reagents of the highest quality were obtained from Sigma (St. Louis, MO).

Cell lines, expression plasmids, and transfections. U937 myelomonocytic and 293 transformed kidney epithelial cells were obtained from the American Type Culture Collection (Rockville, MD) and maintained as previously described $(13,18)$. U937 cells were stimulated with $1 \mathrm{ng} / \mathrm{ml}$ TGF- $\beta_{1}$ and $50 \mathrm{nM} \mathrm{D}{ }_{3}\left(\right.$ TGF- $\left.\beta_{1} / \mathrm{D}_{3}\right)$ for $24 \mathrm{~h}$. This cytokine treatment has been shown to increase expression of $\mathrm{UPA}, \mathrm{UPAR}$, and PAI-1 in this cell line (13). Cell viability throughout the course of the experiments remained greater than $95 \%$ as determined by trypan blue exclusion.

Transfection and subsequent expression of a full coding sequence uPAR cDNA has previously been described (18). Full length PAI-1 cDNA was subcloned into pBluescript II and expression plasmids constructed by inserting the XbaI-XhoI sites into the NheI and XhoI sites of the vector pCEP9. Electroporetic transfection of PAI-1 cDNA $(5 \mu \mathrm{g})$ into uPAR-transfected 293 cells was performed as described (18) with $100 \mu \mathrm{g} / \mathrm{ml}$ hygromycin and $1.35 \mathrm{mg} / \mathrm{ml}$ geneticin as selection agents. After $2 \mathrm{wk}$ in culture, colonies were isolated and maintained separately. Fluorescence-activated cell sorting analysis to determine expression of UPAR in these cells was performed as previously described (19)

Vitronectin binding and adhesion. Vitronectin was purified from human plasma by heparin affinity chromatography in the presence of urea (32). Equilibrium binding of iodinated vitronectin to TGF- $\beta_{1} /$ $\mathrm{D}_{3}$-stimulated U937 cells was performed as previously described (17). Nonspecific binding, determined in the presence of $25 \mathrm{M}$ excess unlabeled vitronectin, accounted for $<10 \%$ of total binding. Adhesion of U937 and 293 cells to vitronectin-coated tissue-culture plastic and binding of biotinylated recombinant suPAR to vitronectin-coated wells was also performed as described previously $(17,18)$.

U937 cell detachment assay. U937 cells $\left(10^{5}\right.$ cells/well $)$ were incubated with TGF- $\beta_{1} / \mathrm{D}_{3}$ with or without $10 \mathrm{nM}$ pro-uPA or ATF in RPMI/10\% FBS in a Falcon 96-well tissue culture plate (BectonDickinson, Mountain View, CA) at $37^{\circ} \mathrm{C}$ for $24 \mathrm{~h}$ to promote adhesion (13). Alternatively, adhesion of TGF- $\beta_{1} / \mathrm{D}_{3}$-stimulated U937 cells to vitronectin-coated wells was induced by the addition of $10 \mathrm{nM}$ prouPA in serum-free medium for $60 \mathrm{~min}$ (17). Spontaneous detachment of U937 cells was examined by replacement of medium with fresh RPMI with or without $10 \%$ FBS followed by incubation at $37^{\circ} \mathrm{C}$ for 0-6 h. PAI-1-induced detachment of U937 cells was investigated by replacement of medium with fresh RPMI with or without caPAI-1 followed by incubation at $37^{\circ} \mathrm{C}$ for $60 \mathrm{~min}$. This PAI-1 preparation was used because of its marked stability in the active state during prolonged incubation at $37^{\circ} \mathrm{C}(33)$. After incubation the wells were rinsed in normal saline to remove nonadherent cells and adherent cells were fixed, stained with Giemsa, and quantified by measuring absorbance at $550 \mathrm{~nm}$ with an automated plate reader (Bio-Rad, Melville, NY) (17).

293 cell detachment assay. UPAR or uPAR/PAI-1 transfectants $\left(10^{5}\right.$ cells per well $)$ were incubated at $37^{\circ} \mathrm{C}$ for $4 \mathrm{~h}$ in a 96 -well tissue culture plate (Falcon Labware, Oxnard, CA) in DME/10\% FBS to promote cellular adhesion. The medium was then replaced with fresh DME with or without FBS containing caPAI-1 and/or $100 \mathrm{nM}$ soluble vitronectin. After incubation at $37^{\circ} \mathrm{C}$ for $24 \mathrm{~h}$, wells were washed and adherent cells fixed, stained, and quantified as described above.

PAI-1 Western blot analysis and ELISA. Conditioned medium from confluent $10-\mathrm{cm}$ dishes of uPAR/PAI-1-transfected 293 cells 
was collected over $24 \mathrm{~h}$ and $1 \mathrm{ml}$ from each clone was lyophilized and subjected to SDS gel electrophoresis in $10 \%$ polyacrylamide under reducing conditions followed by immunoblotting as previously described (13). The primary antibody was a 1:500 dilution of monoclonal mouse anti-human PAI-1 (American Diagnostica, Greenwich, CT), with 1:4,000 peroxidase-labeled goat anti-mouse IgG (Sigma) as the secondary antibody. The blot was developed by chemiluminescence according to the manufacturer's directions (DuPont-NEN, Boston, MA). Conditioned medium was also subjected to PAI-1 ELISA according to manufacturer's directions (American Diagnostica). The presence or absence of FBS in the conditioned medium did not affect levels of PAI-1 as determined by ELISA.

Migration assays. Migration assays were performed in a 96-well chemotaxis chamber using a polyvinylpyrrolidone-free polycarbonate filter with $8-\mu \mathrm{m}$ pores (Neuro Probe, Inc., Cabin John, MD). Where indicated, the top or bottom surfaces of the filter were precoated with $10 \mu \mathrm{g} / \mathrm{ml}$ fibronectin or vitronectin. Filters were washed with PBS, blocked with $\mathrm{PBS} / 1 \% \mathrm{BSA}$ for $60 \mathrm{~min}$ at $37^{\circ} \mathrm{C}$, and washed again. Cells resuspended at $10^{6} / \mathrm{ml}$ in RPMI $/ 0.5 \%$ BSA (U937) or DME/ $0.02 \%$ BSA (293) were added to the upper chamber. caPAI-1 was added to both upper and lower chambers where indicated and, in the case of U397 cells, caPAI-1 was additionally adsorbed onto vitronectin. Chemotaxis of U937 cells was stimulated by addition of $10^{-7} \mathrm{M}$ FMLP in the lower chamber. After incubation at $37^{\circ} \mathrm{C}$ for 2 or $24 \mathrm{~h}$ (U937 or 293 cells, respectively), the top of the filter was scraped with a cell scraper. Migratory 293 cells adherent to the bottom of the filter were fixed in methanol and stained with Giemsa, and cell migration assessed by light microscopy. Migratory U937 cells were noted to fall into the lower chamber where they were quantified via a hemocytometer.

Cleavage of vitronectin. Urea-purified unlabeled $(200 \mu \mathrm{g} / \mathrm{ml})$ or iodinated $(75 \mathrm{ng} / \mathrm{ml})$ vitronectin was subjected to proteolytic cleavage by incubation with plasmin (34), $2 \mu \mathrm{g} / \mathrm{ml}$ or $7.5 \mathrm{ng} / \mathrm{ml}$, respectively, with or without 78 or $10.5 \mu \mathrm{g} / \mathrm{ml}$ aprotinin as indicated at $37^{\circ} \mathrm{C}$. The unmodified mixture was then used for vitronectin binding or adhesion studies in a manner similar to that of uncleaved vitronectin as described above.

Vitronectin was also subjected to cyanogen bromide cleavage (35) as follows. Vitronectin (1.8 $\mathrm{mg})$ was lyophilized, resuspended in $0.75 \mathrm{ml} 70 \%$ formic acid containing $1.8 \mathrm{mg}$ cyanogen bromide, and incubated for $16 \mathrm{~h}$ at room temperature. The mixture was lyophilized again to remove formic acid, resuspended in $20 \mathrm{mM}$ Tris, $\mathrm{pH} 8.0$, and dialyzed against PBS for use in binding and adhesion studies. For some experiments cyanogen bromide-treated vitronectin subsequently underwent plasmin cleavage.

Statistical analysis. Two-tailed Student's $t$ test was performed for comparison of paired mean experimental values. Where depicted, error bars represent the SEM.

\section{Results}

PAI-1 blocks binding of and adhesion to vitronectin mediated by $u P A R$. Vitronectin is the major extracellular matrix binding site of active PAI- 1 and extends the active half-life of this inhibitor which otherwise rapidly becomes latent in solution at $37^{\circ} \mathrm{C}(21)$. Cellular binding of and adhesion to vitronectin by cytokine-stimulated myeloid tumor cells has previously been shown to be mediated by UPAR and is unaffected by the addition of EDTA, arginine-glycine-asparginine (RGD)-containing peptides, or antibodies to $\alpha_{\mathrm{v}} \beta_{5}$ (17), implying that this adhesion is integrin independent. To determine the effect of PAI-1 on the interaction between UPAR and vitronectin, cytokine-stimulated U937 cells were incubated with iodinated vitronectin $(10 \mathrm{nM})$ and increasing amounts of PAI-1. In agreement with our previous results (17), specific binding of vitronectin to cytokine-stimulated myeloid tumor cells was en- hanced by the addition of exogenous uPA (Fig. $1 a$ ). This vitronectin binding was markedly reduced by the concurrent addition of active PAI-1. The effect of PAI-1 was dose-dependent in that addition of $1 \mathrm{nM}$ PAI-1 had little effect on uPA-induced vitronectin binding, $3 \mathrm{nM}$ had an intermediate effect, and $\geq 10$ $\mathrm{nM}$ inhibited binding by over $85 \%$, in agreement with the results of Deng et al. (29).

We next examined the effect of PAI-1 on cellular adhesion to vitronectin. Addition of soluble active PAI-1 to the medium at the time of cell plating markedly impaired cellular adhesion to immobilized vitronectin (Fig. $1 \mathrm{~b}$ ). Precoating adsorbed vitronectin with active PAI-1 before the addition of cells also abrogated cellular adhesion to vitronectin, implying that initial binding of PAI-1 to vitronectin blocks subsequent uPARmediated cellular adhesion. Indeed, at low concentrations adsorbed PAI-1 was more effective than soluble PAI-1 at inhibiting adhesion.

A cell-free system was utilized to determine if PAI-1 directly inhibits the interaction between UPAR and vitronectin. As shown in Fig. $1 c$, active PAI-1 blocks uPA-induced binding of soluble recombinant UPAR to immobilized vitronectin in a dose-dependent fashion. This effect of PAI-1 was noted both in the presence and absence of added UPA. Incubation of PAI-1 at $37^{\circ} \mathrm{C}$ for $24 \mathrm{~h}$ leads to its inactivation (1) and markedly reduces its binding to vitronectin (21). PAI-1 inactivated in this way was ineffective at blocking uPA-induced binding of suPAR to vitronectin (Fig. $1 c$ ). These findings suggest that the PAI-1-induced inhibition of UPAR-vitronectin binding is a result of the known interaction between active PAI-1 and vitronectin.

PAI-1 induces detachment of cells from vitronectin. Because the addition of PAI-1 prevented cellular adhesion to vitronectin (Fig. $1 b$ ), we asked whether subsequent addition of PAI-1 to adherent cells would induce detachment from vitronectin. Incubation of adherent cytokine-stimulated myeloid tumor cells with exogenous active PAI-1 resulted in detachment over $60 \mathrm{~min}$ as shown in Fig. $2 a$. Detachment was induced by PAI-1 in a dose-dependent manner $\left(\mathrm{IC}_{50} \sim 5 \mathrm{nM}\right)$ with a concentration profile similar to that required to inhibit binding of and adhesion to vitronectin by these cells (Fig. 1, $a$ and $b$ ) and binding of suPAR to immobilized vitronectin (Fig. $1 \mathrm{c}$ ). This effect of PAI-1 was similar whether cell attachment was induced by uPA over $24 \mathrm{~h}$ in serum (as depicted in Fig. $2 a$ ) or over $1 \mathrm{~h}$ in serum-free media to immobilized vitronectin (data not shown). Furthermore, addition of PAI-1 resulted in cellular detachment when attachment was induced by either a relatively inactive precursor (pro-uPA) or a catalytically inactive receptor-binding fragment (ATF) of uPA. As PAI-1 binds poorly to the former (1) and not at all to the latter, these data suggest that cellular detachment induced by PAI-1 is a result of a direct interaction between PAI-1 and immobilized vitronectin and is not mediated by a PAI-1/uPA interaction or induction of cell-surface uPA turnover by PAI-1 (13).

Addition of exogenous PAI-1 decreased adhesion of cytokine-stimulated U937 cells to vitronectin (Fig. $1 b$ and Fig. 2 a). As cytokine stimulation markedly upregulates PAI-1 expression in these cells (13), we postulated that endogenous production of PAI-1 might also result in detachment. U937 cells stimulated with cytokines in the presence of uPA and serum are adherent at $24 \mathrm{~h}$ and remain so for up to $48 \mathrm{~h}$ thereafter (data not shown). However, spontaneous detachment occurs over several hours after a change from serum-containing 
a

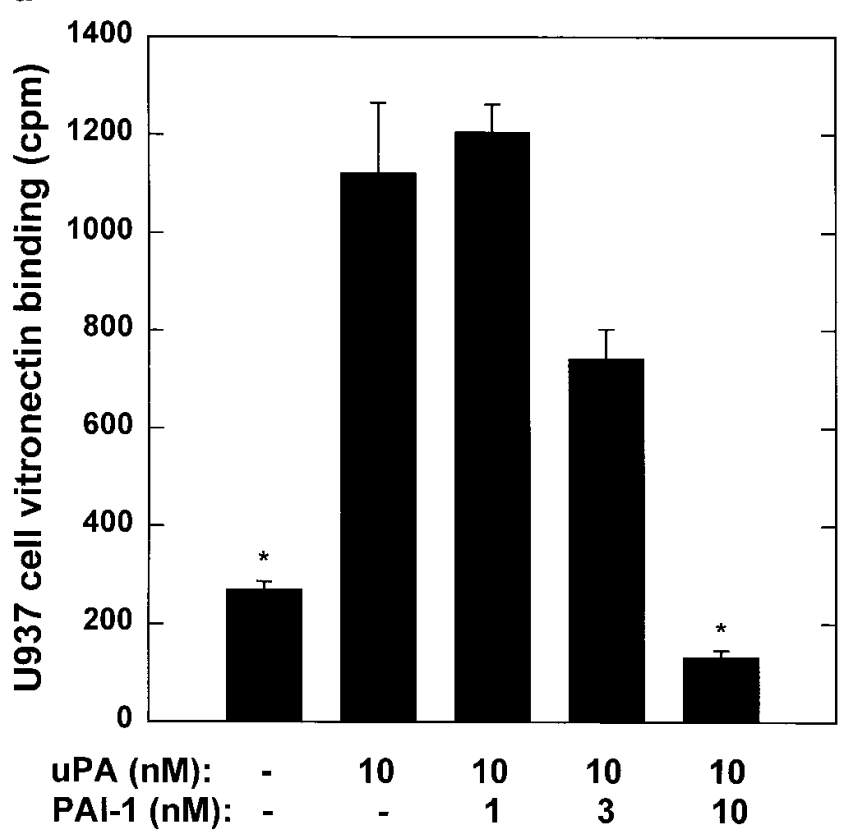

C

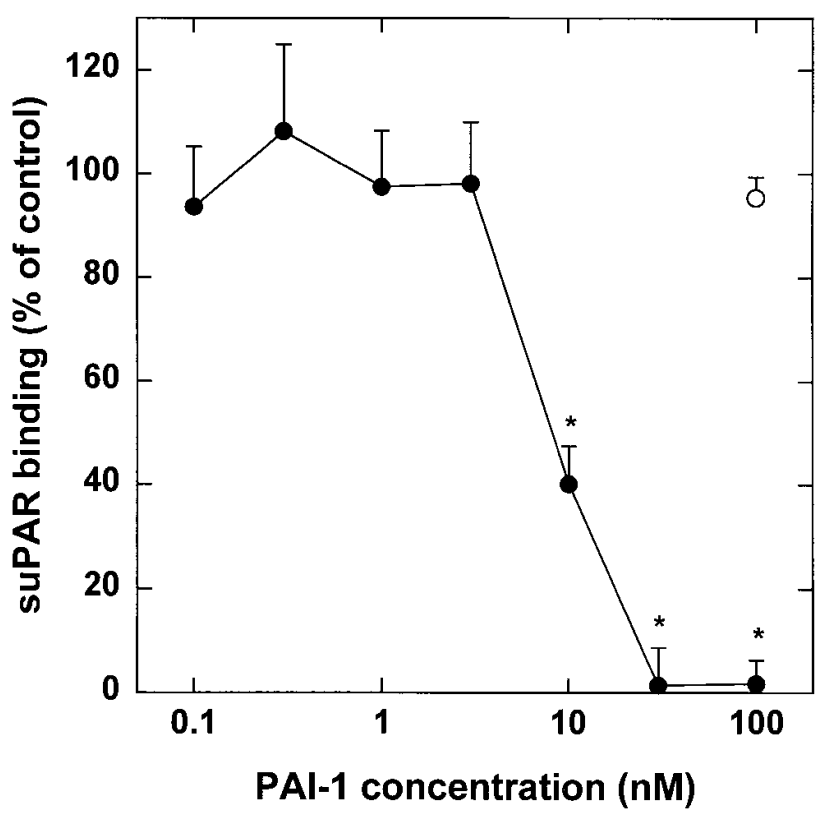

to serum-free media. Cell adhesion after $2 \mathrm{~h}$ in serum-free media is $\sim 80 \%$ of baseline and falls to $20 \%$ at 4 and $6 \mathrm{~h}$. Cell viability was similar in serum-containing and serum-free media over this time. We hypothesized that serum may reduce detachment by providing a source of soluble vitronectin to which endogenously produced PAI-1 would bind, thus decreasing the amount of PAI-1 available to interact with adsorbed vitronectin. As seen in Fig. $2 a$, the addition of soluble vitronectin blocked the induction of cellular detachment by exogenous PAI-1. Thus it appears that binding of PAI-1 to soluble vitronectin reduces binding of PAI-1 to adsorbed vitronectin, abrogating PAI-1-induced cellular detachment.

To determine more directly if endogenous PAI-1 induces b

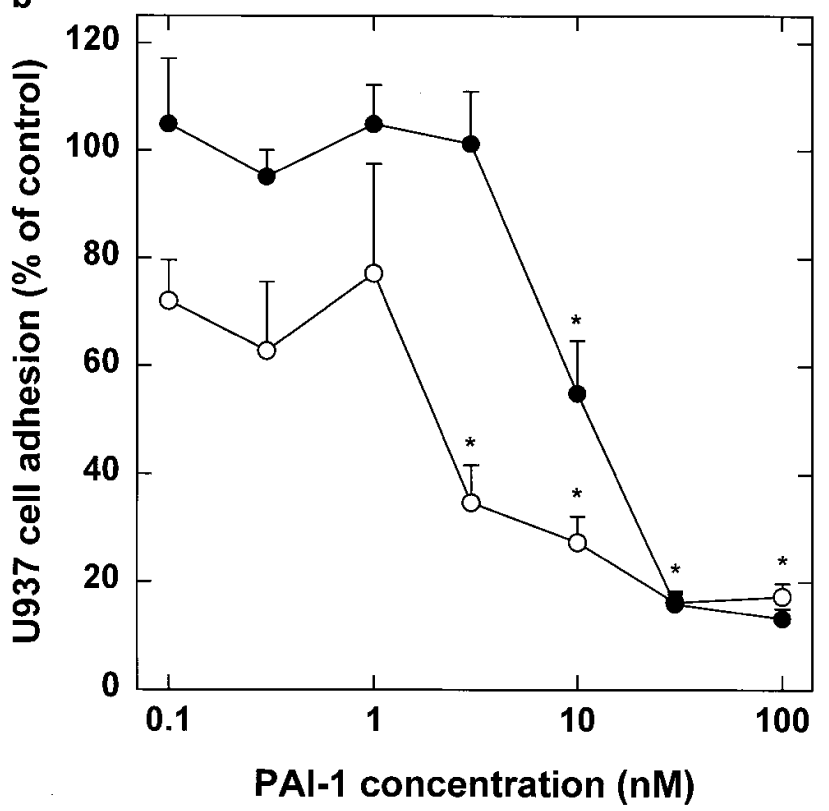

Figure 1. Effect of PAI-1 on (a) cellular binding of, $(b)$, cellular adhesion to, and (c) soluble uPAR binding to vitronectin. (a) TGF- $\beta_{1} / \mathrm{D}_{3^{-}}$ primed U937 cells were incubated with $10 \mathrm{nM}{ }^{125}$ I-vitronectin in the absence or presence of pro-uPA and/or PAI-1 as indicated. After $90 \mathrm{~min}$ at $4^{\circ} \mathrm{C}$ specific binding was determined. Results shown are the mean of triplicate determinations from a representative $(n=5)$ experiment. $* P<$ 0.05 vs. pro-uPA alone. $(b)$ Adsorbed vitronectin was incubated with media in the presence (open circle) or absence (closed circle) of PAI-1 for $60 \mathrm{~min}$. TGF- $\beta_{1} / \mathrm{D}_{3}$-stimulated U937 cells were then seeded in fresh serum-free media at $10^{5}$ cells per well with $10 \mathrm{nM}$ pro-uPA with (closed circle) or without (open circle) soluble PAI-1. After incubation at $37^{\circ} \mathrm{C}$ for $60 \mathrm{~min}$, nonadherent cells were rinsed off, and adherent cells quantified by fixation in methanol followed by Giemsa staining and measurement of absorption at $550 \mathrm{~nm}$. Results shown are the mean of triplicate determinations from three (adsorbed PAI-1) or six (soluble PAI-1) separate experiments and are expressed as a percentage of the uPA-induced adhesion seen to vitronectin in the absence of PAI- 1 (control). $* P<0.05$ vs. control. (c) Vitronectin-coated wells were blocked with 1\% BSA and incubated with $5 \mathrm{nM}$ biotinylated suPAR and $10 \mathrm{nM}$ DFP-uPA in the presence of active PAI-1 (closed circle) as indicated for $60 \mathrm{~min}$ on ice. In some samples PAI-1 had previously been inactivated by incubation at $37^{\circ} \mathrm{C}$ for $24 \mathrm{~h}$ (open circle). Results from triplicate determinations of three separate experiments are expressed as a percentage of uPA-dependent suPAR binding in the absence of PAI- 1 (control). ${ }^{*} P<0.05$ vs. control.

cellular detachment we stably co-transfected transformed renal epithelial (293) cells with both uPAR and PAI-1. Transfection with $\mathrm{UPAR}$ alone renders these cells strongly adhesive to serum-coated plastic and this adhesion is mediated by the interaction between uPAR and vitronectin (18). Several cotransfected clones were isolated with varying degrees of PAI-1 expression (Fig. 2 b, bottom). Expression of uPAR in these clones as determined by fluorescence-activated cell sorting analysis did not vary by more than $10 \%$ (data not shown). Relative amounts of PAI-1 expression as determined by Western blot were confirmed by ELISA utilizing an antibody that recognizes both active and latent forms of PAI-1. Concentrations of PAI-1 in conditioned media collected over $24 \mathrm{~h}$ ranged from 
a

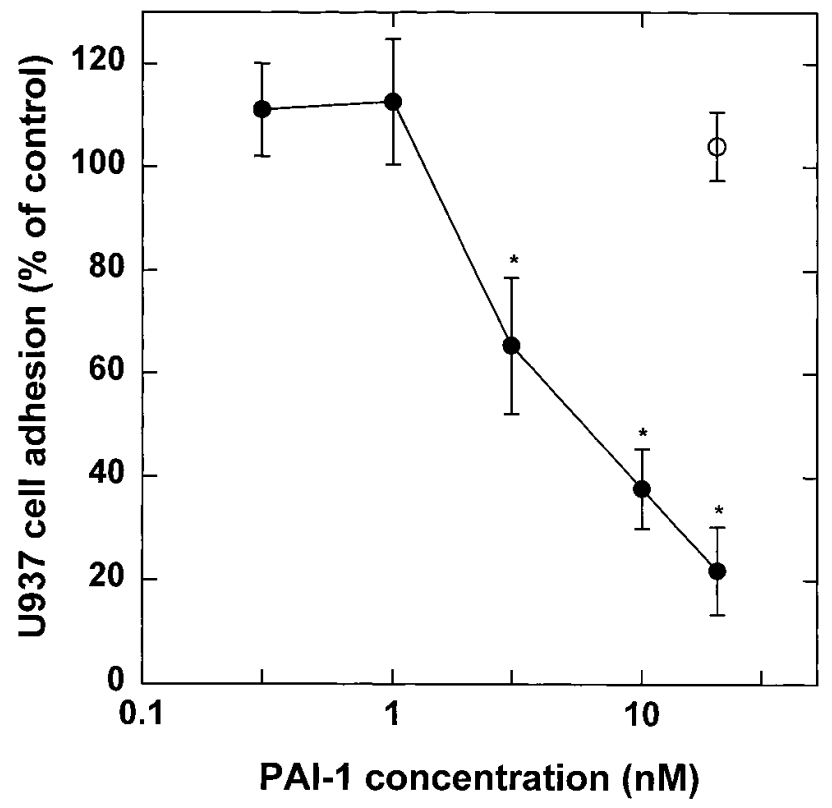

b

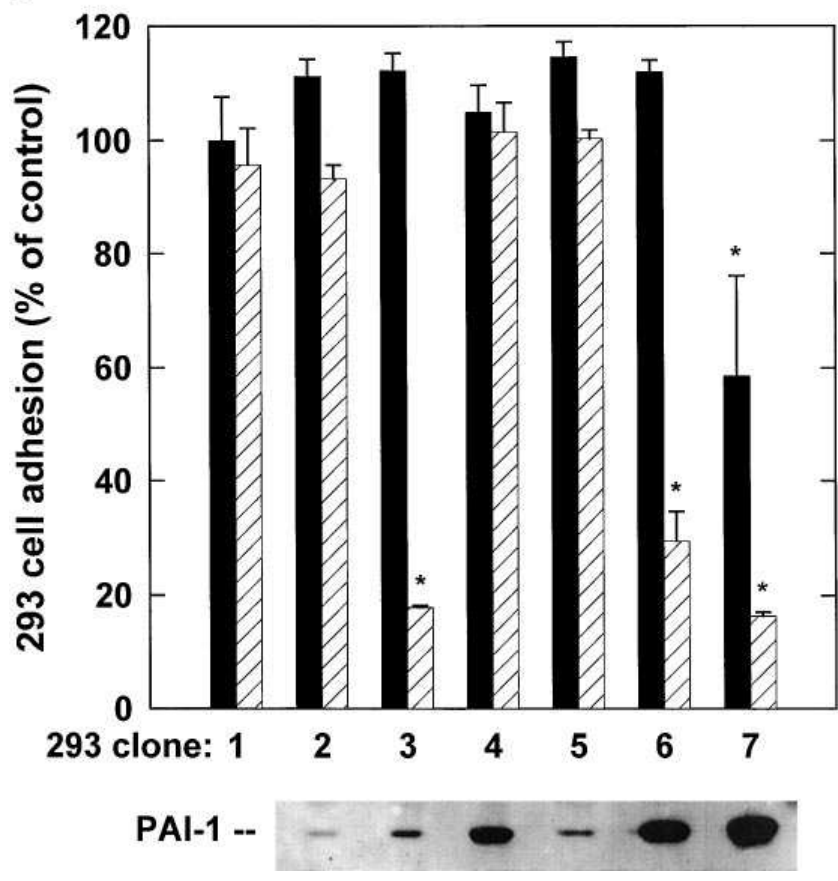

Figure 2. PAI-1 promotes detachment of (a) U937 and (b) uPARtransfected 293 cells from vitronectin. (a) U937 cells were primed with TGF- $\beta_{1} / \mathrm{D}_{3}$ and pro-uPA in $10 \%$ FBS for $24 \mathrm{~h}$; ATF was substituted for pro-uPA in the samples containing $20 \mathrm{nM}$ PAI-1. Fresh media with caPAI-1 without (closed circle) or with (open circle) $100 \mathrm{nM}$ soluble vitronectin was then added and the plates washed after 60 $\min$ at $37^{\circ} \mathrm{C}$. Mean adhesion from three experiments, each performed in triplicate, is expressed as a percent of adhesion seen in the absence of exogenous PAI-1 (control). ${ }^{*} P<0.05$ vs. control. (b) 293 cells transfected with uPAR alone (clone 1) or UPAR and PAI-1 (clones 2-7) were cultured for $24 \mathrm{~h}$ in serum-free media (striped bars), or media containing $10 \%$ FBS (solid bars), and adhesion was determined. Adhesion is expressed as a percent of that seen in clone 1 cultured in $10 \%$ FBS (control) and reflects the mean of triplicate determinations from two independent experiments. $* P<0.05$ vs. clone 1 . Western blot analysis of PAI-1 expression in conditioned media containing undetectable (clone 1 ) to $<20 \mathrm{nM}$ (clones 2, 3, and 5) to 75$200 \mathrm{nM}$ (clones 4, 6, and 7) (data not shown). Spontaneous detachment after $24 \mathrm{~h}$ in serum-free media was noted in some of the co-transfected clones but was not seen following uPAR transfection alone (Fig. $2 \mathrm{~b}$, top). Only those clones with the greatest amount of PAI-1 expression were noted to detach. Indeed, the clone with the highest PAI-1 expression, clone 7, detached spontaneously even in the presence of serum and required lysine-coated tissue-culture plastic for maintenance in culture. Addition of $30-100 \mathrm{nM}$ exogenous caPAI-1 to uPAR-expressing 293 cells (clone 1) resulted in cellular detachment (data not shown). This detachment was blocked by soluble vitronectin in a manner similar to that seen with U937 cells (Fig. 2 a). Addition of PAI-1 to untransfected 293 cells did not affect adhesion to vitronectin (data not shown). Taken together, these results demonstrate that PAI-1, from both exogenous and endogenous sources, induces cellular detachment from vitronectin when adhesion is mediated by UPAR.

PAI-1 promotes migration of $u P A R$-expressing cells on vitronectin. Cellular migration is dependent upon transient attachment to and then detachment from a substrate (23). We thus sought to determine if PAI-1-induced modulation of cellular adhesion to vitronectin would affect migration. As seen in Fig. $3 a$, cytokine-stimulated U937 cells exhibited migration across a porous filter over $2 \mathrm{~h}$ in an FMLP gradient. This migration is markedly diminished if the top surface of the filter is coated with vitronectin. The addition of $10 \mathrm{nM}$ ATF, which promotes adhesion of these cells to vitronectin (17), further reduces migration. The reduction in migration induced by ATF is abrogated by the addition of $20 \mathrm{nM}$ PAI-1, a concentration that markedly reduces cellular adhesion to vitronectin (Fig. 1b).

We also examined the effects of PAI-1 on haptotactic motility of uPAR-expressing 293 cells. Little migration was seen over $24 \mathrm{~h}$ when the upper and lower surfaces of a porous polycarbonate filter were coated with albumin (Fig. $3 b$ ). Migration onto the lower surface of the filter is increased severalfold when a haptotactic gradient is provided by fibronectin (Fig. 3a). Precoating the top surface of the filter with vitronectin, to which these cells avidly adhere $(18,19)$, significantly retards migration. The addition of $20 \mathrm{nM}$ soluble PAI-1 under these circumstances markedly enhances migration and reverses the inhibitory effect of vitronectin. These data underscore the inverse relationship between adhesion to vitronectin and cellular migration in these model systems, and demonstrate a direct role for PAI-1 in enhancing the migration of UPAR-expressing cells on vitronectin.

Plasmin cleavage of vitronectin reduces cellular binding and adhesion and induces cellular detachment. Limited proteolysis of vitronectin by plasmin has been used to map binding sites for PAI-1 on vitronectin (36-38). As PAI-1 binding abrogates uPAR-mediated cellular adhesion to and binding of vitronectin, the effects of plasmin cleavage of vitronectin on subsequent cellular binding and adhesion were examined. The initial plasmin cleavage site in vitronectin is at residue 361 in the heparin-binding domain of the molecule (36). As shown in Fig. $4 a$, incubation of soluble vitronectin with plasmin results in limited proteolysis initially generating fragments of 63,12 , and $2 \mathrm{kD}$ followed by formation of additional fragments of 42 and

$10 \%$ FBS from clones $2-7$ is displayed at the bottom of the figure; similar results were seen in serum-free media. 


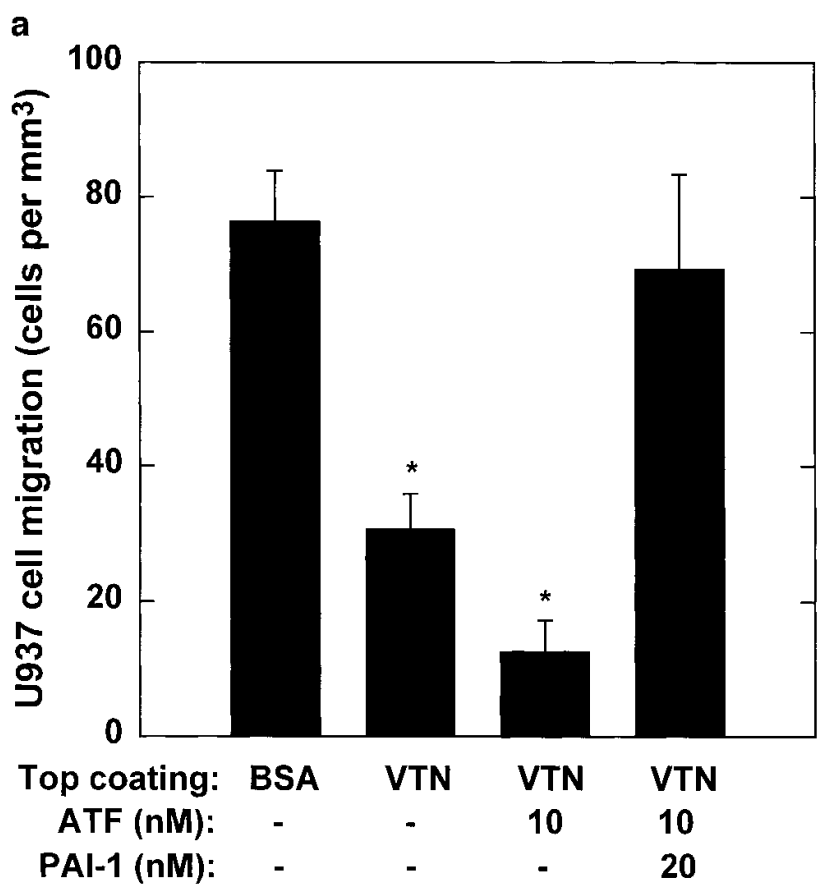

b

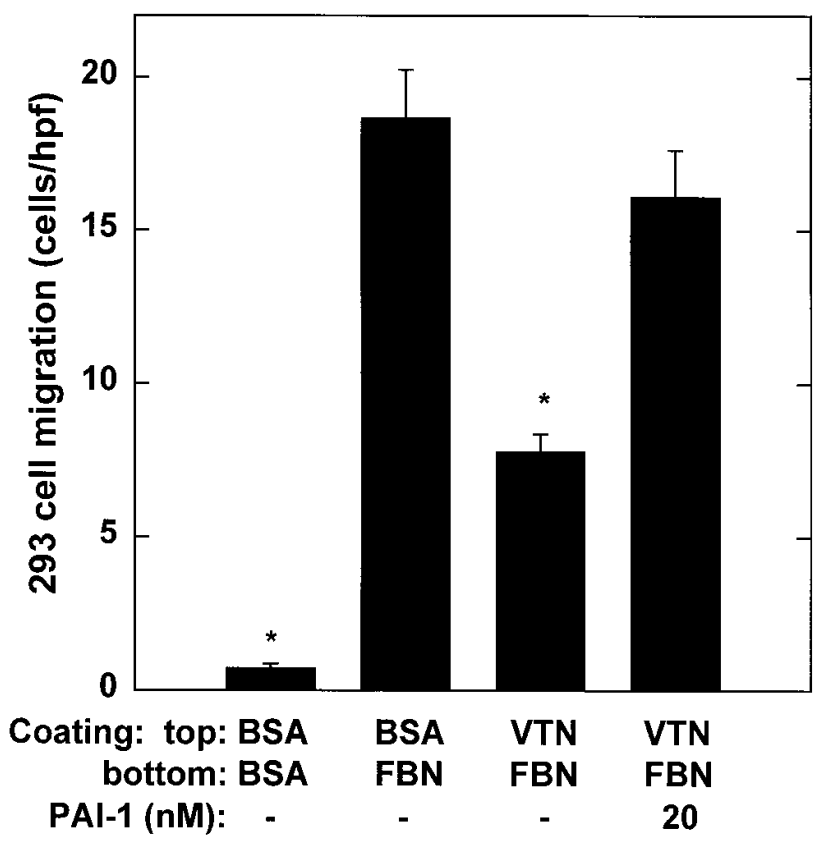

Figure 3. Migration of uPAR-expressing U937 ( $a$ ) and 293 (b) cells. Polycarbonate filters precoated with $10 \mu \mathrm{g} / \mathrm{ml}$ fibronectin (FBN) or $10 \mu \mathrm{g} / \mathrm{ml}$ vitronectin (VTN) on the top or bottom surface as indicated were blocked with PBS/BSA and loaded in a chemotaxis chamber.

(a) TGF- $\beta_{1} / \mathrm{D}_{3}$-stimulated U937 cells were added to the top chamber, $10^{-7} \mathrm{M}$ FMLP to the bottom chamber, and ATF and/or caPAI- 1 to both chambers as indicated. In samples containing soluble PAI-1, $20 \mathrm{nM}$ caPAI-1 was also adsorbed onto the top surface vitronectin before plating of cells. Cells falling into the lower chamber after incubation at $37^{\circ} \mathrm{C}$ for $2 \mathrm{~h}$ were counted via a hemocytometer. Results reflect the mean of triplicate determinations from three separate experiments. ${ }^{*} P<0.05$ vs. BSA alone. (b) 293 cells transfected with uPAR were added to the top chamber and caPAI-1 was added to both top and bottom chambers as indicated. Migration of cells onto the bottom surface of the membrane was determined by light micros-
$35 \mathrm{kD}$ (39). Both adhesion to and binding of vitronectin by cytokine-stimulated myeloid cells are rapidly attenuated by plasmin cleavage (Fig. $4 b$ ). This effect is specific for plasmin-mediated proteolysis as cleavage of vitronectin at residues 341 and possibly 381 by cyanogen bromide (35) had no effect on either vitronectin adhesion or binding by cytokine-stimulated U937 cells (data not shown). Subsequent exposure to plasmin, however, abrogated the ability of cyanogen bromide-cleaved vitronectin to promote cellular adhesion and binding.

We next sought to determine the effects of plasmin cleavage on cellular adhesion to adsorbed vitronectin. Urea-purified vitronectin adsorbed to tissue-culture plastic was incubated with $1 \mu \mathrm{g} / \mathrm{ml}$ plasmin for $60 \mathrm{~min}$ at $37^{\circ} \mathrm{C}$ with or without aprotinin. Non-specific binding sites were blocked with BSAcontaining PBS before and after plasmin incubation. Adhesion of suPAR-transfected 293 cells or TGF- $\beta_{1} / D_{3}$-stimulated U937 cells in the presence of $10 \mathrm{nM}$ ATF was reduced to $<5 \%$ of control values by this in situ plasmin cleavage (data not shown). In these experiments incubation of cells with plasmin prior to plating onto vitronectin did not diminish adhesion. Conversely, incubation of adherent cells with plasmin resulted in subsequent detachment ( $>95 \%$ ) which was blocked by the presence of aprotinin (not shown). While it is possible that the latter results may in part reflect nonspecific effects of plasmin on attached cells, the data reported in this section demonstrate that proteolytic cleavage of vitronectin by plasmin alters a binding site for UPAR important to cellular adhesion.

Peptide mapping of a plasmin cleavage site in vitronectin identifies sequences important in suPAR binding. As vitronectin binding and adhesion was rapidly attenuated by incubation with plasmin, we generated synthetic peptides around residue 361 and determined their effects on UPAR binding. As shown in Table I, peptides VN-3 and VN-4 reduced binding of soluble recombinant uPAR to vitronectin with an $\mathrm{IC}_{50}$ of $\sim 8$ and $\sim 25$ $\mu \mathrm{M}$, respectively. Peptides VN-1 and VN-2, representing other nearby vitronectin sequences, and peptides SC-3 and SC-4, scrambled versions of VN-3 and VN-4, had no effect on uPAR binding at concentrations up to $500 \mu \mathrm{M}$. We were unable to determine the effects of these peptides on uPAR-dependent cellular adhesion to vitronectin, as they promoted uPA-independent adhesion of cytokine-stimulated U937 cells (not shown), possibly through nonspecific charge associations related to their basic nature. Nevertheless, the data shown in Fig. 4 and Table I indicate a role for the heparin-binding domain of vitronectin in interactions with UPAR.

\section{Discussion}

Results of experiments detailed above indicate that the interactions of UPAR with vitronectin are regulated by components of the uPA/plasmin system. The avidity of uPAR for vitronectin is strongly promoted by occupancy of the receptor with uPA. However, the findings that both PAI-1 and plasmin inhibit this avid association implies that under physiological conditions uPAR-dependent cellular attachment to vitronectin is likely only transient. uPAR occupancy by uPA sufficient to

copy after $24 \mathrm{~h}$ at $37^{\circ} \mathrm{C}$. Results reflect the mean of five determinations of cell number per high-powered field in triplicate samples from two separate experiments. $* P<0.05$ vs. FBN alone. 
a

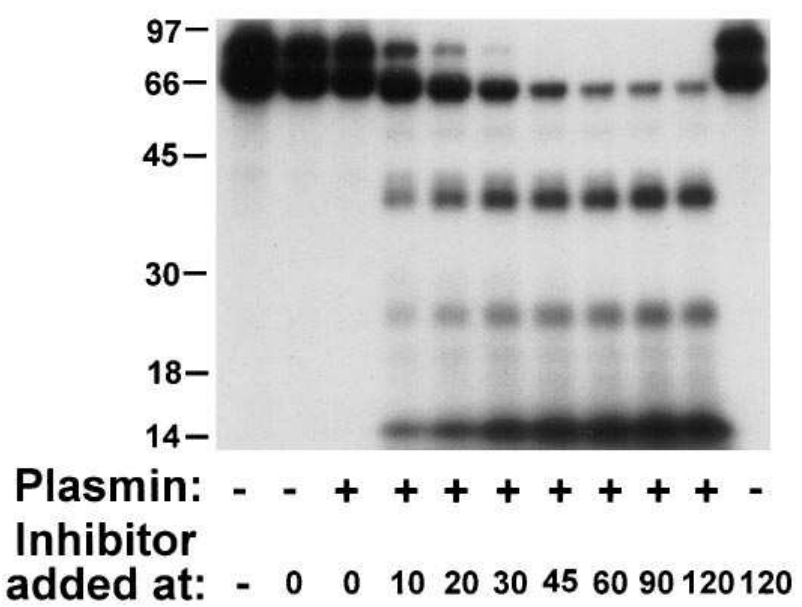

b

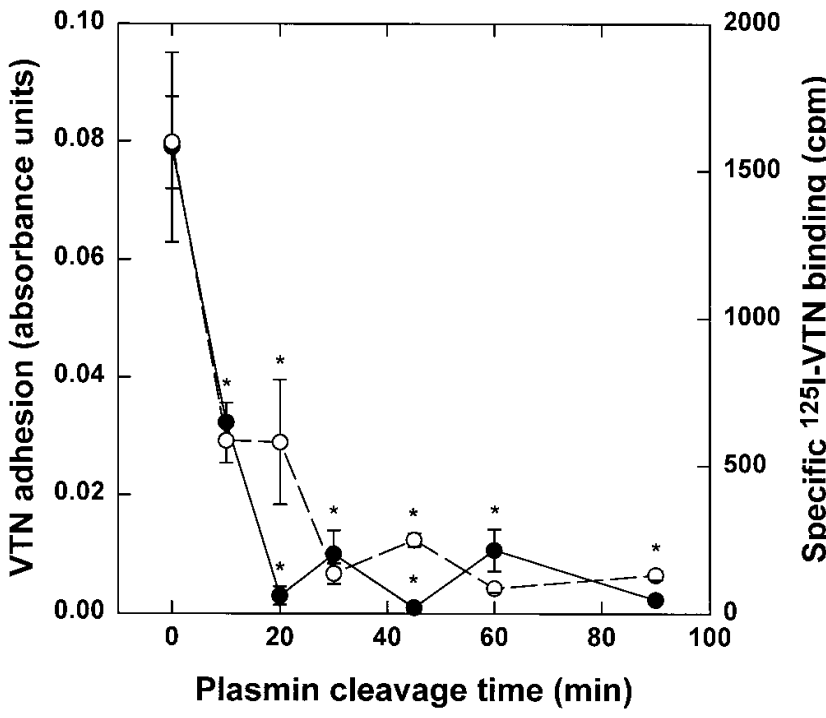

Figure 4. Effect of plasmin cleavage on U937 cell binding of and adhesion to vitronectin. (a) Autoradiograph of plasmin-cleaved ${ }^{125} \mathrm{I}$-vitronectin. Iodinated vitronectin (left lane) was incubated at $37^{\circ} \mathrm{C}$ for $2 \mathrm{~h}$ without or with plasmin. Aprotinin was added to solution at the times indicated and the samples electrophoresed in a reduced $10 \%$ SDS-polyacrylamide gel followed by autoradiography. Migration of molecular weight standards (in $\mathrm{kD}$ ) is indicated to the left of the figure. A similar cleavage pattern was seen by Coomassie blue staining of unlabeled vitronectin subjected to plasmin cleavage followed by gel electrophoresis. (b) TGF- $\beta_{1} / \mathrm{D}_{3}$-stimulated U937 cell binding of (open circle) and adhesion to (closed circle) plasmin-cleaved vitronectin. Cellular adherence to adsorbed unlabeled vitronectin treated with plasmin as described above was determined in the presence of $10 \mathrm{nM}$ pro-uPA and is expressed in absorbance units. Specific binding of plasmin-cleaved ${ }^{125} \mathrm{I}$-vitronectin to U937 cells in the presence of $10 \mathrm{nM}$ pro-uPA is expressed in counts per minute. The results shown reflect the means of triplicate determinations from representative experiments $(n=3) . * P<0.05$ vs. time 0 .

promote cellular adhesion to vitronectin could also be expected to generate local plasmin activity and effect cellular detachment. Conversely, sufficient PAI-1 to block generation of plasmin by receptor-bound uPA could be expected to promote detachment of cells by either of two mechanisms. First, PAI-1
Table I. Effect of Vitronectin Peptides on Binding of Soluble Biotinylated $u P A R$ to Immobilized Vitronectin

\begin{tabular}{lccr}
\hline Peptide & VTN residues & Concentration & Binding \\
\hline & & $\mu M$ & \\
VN-1 & $347-356$ & 500 & $110.1 \pm 3.8$ \\
VN-2 & $357-366$ & 500 & $98.4 \pm 5.4$ \\
VN-3 & $371-380$ & 1 & $86.3 \pm 4.1$ \\
VN-3 & $371-380$ & 10 & $46.0^{*} \pm 4.0$ \\
VN-3 & $371-380$ & 100 & $11.4^{*} \pm 4.0$ \\
VN-4 & $364-375$ & 1 & $96.3 \pm 0.7$ \\
VN-4 & $364-375$ & 10 & $52.9^{*} \pm 0.4$ \\
VN-4 & $364-375$ & 100 & $11.6^{*} \pm 1.2$ \\
SC-3 & - & 500 & $113.2 \pm 9.7$ \\
SC-4 & - & 500 & $107.2 \pm 9.4$ \\
& & & \\
\hline
\end{tabular}

Binding of suPAR to immobilized vitronectin in the presence of $10 \mathrm{nM}$ ATF and the indicated peptides was determined as described in Methods. The results reflect triplicate values from two independent experiments expressed as a percentage of binding in the absence of peptides (control). ${ }^{*} P<0.05$ vs. control. The major plasmin cleavage site in vitronectin is at residue 361 .

promotes clearance of uPA from $\operatorname{uPAR}(13,40)$, which would decrease uPAR occupancy and thus cellular attachment to vitronectin. Second, cellular detachment could be effected by direct inhibition of $\mathrm{uPAR} /$ vitronectin interactions by PAI-1 as documented in the present study and previous reports $(29,30)$. Indeed, PAI-1 appears capable of not only blocking initial binding of vitronectin to uPAR but also of effecting actual detachment of cells already bound. A prediction of this paradigm is that excess PAI- 1 might actually promote cellular migration over vitronectin-coated surfaces by abrogating stable interactions with vitronectin. This prediction was verified experimentally in migration assays (Fig. 3). In the presence of vitronectin, PAI-1 clearly promoted migration of both U937 cells and uPAR-transfected 293 cells across vitronectin. Alternatively, the presence of plasmin would also be expected to promote cellular migration, and this has been previously demonstrated in vitro $(41,42)$. A second prediction is that occupancy of uPAR by agonists that promote vitronectin binding but can neither activate plasmin nor interact with PAI-1 could inhibit migration by promoting stable rather than transient cell:matrix contacts, also observed in Fig. 3. This scenario may explain, at least in part, prior results showing that "inhibition" of uPAR by saturation of the receptor with an inactive amino-terminal fragment of uPA in vivo blocked metastasis in experimental models of tumor progression (43-45).

Although uPAR clearly has the capacity to act as an adhesion receptor, available data indicate that not all cells expressing UPAR utilize this receptor to adhere to vitronectin. Kanse et al., for example, found endothelial cell adhesion to vitronectin to be exclusively RGD sensitive and not blocked by uPAR antibodies even though the major vitronectin binding site on the cells appeared to be uPAR (30), suggesting that these cells adhere to vitronectin via integrins yet also bind vitronectin via uPAR. Similarly, we have found adhesion of human alveolar macrophages to vitronectin to be completely RGD and EDTAsensitive even though these cells express relatively large amounts of uPAR (Rao, N.K., and H.A. Chapman, unpublished obser- 
vations). However, in vitro migration of macrophages across vitronectin-coated membranes was sensitive to UPAR antibodies and largely abrogated by saturation of UPAR with inactive urokinase (Waltz, D.A., unpublished observations), consistent with the regulatory scheme described above. Thus it may be that some cells utilize UPAR as part of their migratory machinery even though the receptor is not part of normal adhesion. It remains to be defined what molecular constraints regulate the capacity of UPAR to function in adhesion and migration.

The mechanism by which PAI-1 induces cellular detachment from vitronectin is unclear. Direct binding of PAI-1 to vitronectin appears to be required (Fig. 1). The simplest explanation is that PAI-1 and UPAR compete for a common binding site on vitronectin. As the somatomedin domain is a known high-affinity binding site for PAI-1 on vitronectin (46), this domain could be such a site. This possibility is supported by recently reported results that recombinant, purified somatomedin B domain, as well as antibodies to this domain, inhibit binding of recombinant soluble UPAR to immobilized vitronectin (29). Another PAI-1 binding site on vitronectin has been reported near a plasmin cleavage site in the heparin-binding domain (36-38). Cleavage of vitronectin by plasmin (Fig. 4), but not cyanogen bromide, markedly reduces cellular binding and adhesion, suggesting that this region is also important to uPAR/vitronectin interactions. The results of mapping experiments with synthetic peptides surrounding this cleavage site (Table I) support this prediction. Overall, our data favor the view that PAI-1 interacts directly with vitronectin, likely near the plasmin cleavage site at residue 361, thereby reducing its affinity for UPAR.

Our findings that UPAR and PAI-1 regulate adhesion and migration of cells independently of, though influenced by, urokinase, implies an intrinsic duality of the uPA/plasmin system. Under some conditions, especially in the context of exuberant extravascular fibrin deposition, regulation of the protease activities of uPA and plasmin are rate-limiting in fibrin turnover, wound healing, and the ability of cells to move through tissues. Reported observations in plasminogen-deficient mice (2), in mice overexpressing PAI-1 (47), and in several models of tumor metastasis $(43,48,49)$ are recent verifications of this long-held paradigm. Cell-surface protease activity would appear to be transient and cyclic, as judged by the ability of UPAR itself to recycle following turnover of uPA/PAI complexes (4). Based on observations reported here, these dynamic events could also be expected to effect parallel cycles of enhanced and depressed cellular adhesiveness. We favor the view that these cycles of adhesiveness are synergistic with the protease arm of this system in promoting migration. This view is supported by previously reported data indicating that PAI-1 could synergize with uPA in promoting tumor cell motility in vitro $(42,50)$. Why should adhesion be coupled to the protease activity of the uPA/plasmin system? By providing offsetting changes in adhesiveness, this linkage may promote cellular migration without precise regulation of the protease arm of the system. High levels of UPAR occupancy by uPA, unopposed by PAI-1, while promoting attachment would also promote plasmin activity and detachment. Conversely, high levels of PAI-1 would prevent stable adhesion in the event no plasmin was available. The duality of this system allows a plasticity not present in the protease system alone. This plasticity may be particularly relevant in disease states characterized by accumulation of vitronectin and PAI-1, such as atheroma $(27,51)$, acute inflammatory reactions in the lung $(9,26)$, and several cancerous states (52-57). Excess PAI-1, while promoting persistence of fibrin and subsequent scarification (47), may also promote inflammatory and tumor cell mobility within the provisional matrix.

Results of the experiments reported here, and previously by us and others, underscore the intricate relationship between adhesion and migration $(19,24)$. Cellular migration is potentially both promoted and retarded at the same time by the complex of attachment sites within an extracellular matrix. As we demonstrate here in haptotactic migration assays, the addition of vitronectin and uPA fragments which promote adhesion to vitronectin markedly retards cell migration from vitronectin onto fibronectin (Fig. $3 b$ ). In this setting PAI-1 clearly promotes haptotactic migration toward fibronectin. Similarly, uPAR occupancy retards and PAI-1 promotes chemotactic migration across vitronectin (Fig. $3 a$ ). Although we have not proven that the cells migrating in the presence of PAI-1 have actually detached from vitronectin, we think the strong inverse correlation between strength of adhesion to vitronectin and propensity to migrate favors this view. In contrast, in migration assays in which cells move toward vitronectin, the strength of attachment to vitronectin directly correlates with migratory potential. Cells expressing uPAR adhere to vitronectin and migrate toward vitronectin much better than cells not expressing or unable to use UPAR to adhere to vitronectin (19). In this setting, PAI-1 may actually inhibit migration. Indeed, this result was recently reported by Stefansson and Lawrence who demonstrated that PAI-1 inhibited $\alpha_{\mathrm{v}} \beta_{3}$-dependent migration of smooth muscle cells toward vitronectin (58), presumably by inhibiting interactions between $\alpha_{v} \beta_{3}$ and vitronectin. Given the complex relationship between adhesion and migration in vitro, are there clues as to the dominant effects of PAI-1 on migration in vivo? There is a strong correlation between metastasis, poor survival, and PAI-1 expression in some experimental tumor models $(42,50)$ and numerous clinical studies of cancer (59-61). These studies suggest that the dominant effect of PAI-1 in tumor biology may be to promote cell migration. It will be important to determine if our observations that PAI-1 can promote cellular detachment from and migration across vitronectin in vitro underlies, at least in part, the accumulating evidence linking PAI-1 to malignant cellular behavior in vivo.

\section{Acknowledgments}

We thank Drs. Navaneetha Rao and Daniel Simon for critical review of the manuscript.

This study was supported by the National Institutes of Health (HL-03169-01 and HL-44712) and the American Lung Association (RG-038-N).

\section{References}

1. Saksela, O., and D.B. Rifkin. 1988. Cell-associated plasminogen activation: regulation and physiological functions. Annu. Rev. Cell Biol. 4:93-126.

2. Romer, J., T.H. Bugge, C. Pyke, L.R. Lund, M.J. Flick, J.L. Degen, and K. Dano. 1996. Impaired wound healing in mice with a disrupted plasminogen gene. Nature Med. 2:287-292.

3. Vassalli, J.-D., A.-P. Sappino, and D. Belin. 1991. The plasminogen activator/plasmin system. J. Clin. Invest. 88:1067-1072.

4. Blasi, F. 1993. Urokinase and urokinase receptor: a paracrine/autocrine system regulating cell migration and invasiveness. BioEssays. 15:105-111.

5. Vaheri, A., R.W. Stephens, E.-M. Salonen, J. Pollanen, and H. Tapiovaara. 1990. Plasminogen activation at the cell surface-matrix interface. Cell Differ. Dev. 32:255-262. 
6. Plow, E.F., D.E. Freaney, J. Plescia, and L.A. Miles. 1986. The plasminogen system and cell surfaces: evidence for plasminogen and urokinase receptors on the same cell type. J. Cell Biol. 103:2411-2420.

7. Vassalli, J.-D., D. Baccino, and D. Belin. 1985. A cellular binding site for the $M_{\mathrm{r}} 55,000$ form of the human plasminogen activator, urokinase. J. Cell Biol. 100:86-92.

8. Ploug, M., E. Ronne, N. Behrendt, A.L. Jensen, F. Blasi, and K. Dano. 1991. Cellular receptor for urokinase plasminogen activator: carboxyl-terminal processing and membrane anchoring by glycosyl-phosphatidylinositol. J. Biol. Chem. 266:1926-1933.

9. Bertozzi, P., B. Astedt, L. Zenzius, K. Lynch, F. LeMaire, W. Zapol, and H.A. Chapman. 1990. Depressed bronchoalveolar urokinase activity in patients with adult respiratory distress syndrome. N. Engl. J. Med. 322:890-897.

10. Podor, T.J., P. Joshua, M. Butcher, D. Seiffert, D. Loskutoff, and J. Gauldie. 1992. Accumulation of type 1 plasminogen activator inhibitor and vitronectin at sites of cellular necrosis and inflammation. Ann. N.Y. Acad. Sci. 667: 173-177.

11. Fazioli, F., and F. Blasi. 1994. Urokinase-type plasminogen activator and its receptor: new targets for anti-metastatic therapy? Trends Pharmacol. Sci. 15:25-29.

12. Nusrat, A.R., and H.A. Chapman. 1991. An autocrine role for urokinase in phorbol ester-mediated differentiation of myeloid cell lines. J. Clin. Invest. 87:1091-1097.

13. Waltz, D.A., L.Z. Sailor, and H.A. Chapman. 1993. Cytokines induce urokinase-dependent adhesion of human myeloid cells: a regulatory role for plasminogen activator inhibitors. J. Clin. Invest. 91:1541-1552.

14. Estreicher, A., J. Muhlhauser, J.-L. Carpentier, L. Orci, and J.-D. Vassalli. 1990. The receptor for urokinase type plasminogen activator polarizes expression of the protease to the leading edge of migrating monocytes and promotes degradation of enzyme inhibitor complexes. J. Cell Biol. 111:783-792.

15. Stahl, A., and B.M. Mueller. 1994. Binding of urokinase to its receptor promotes migration and invasion of human melanoma cells in vitro. Cancer Res. 54:3066-3071.

16. Rosso, M.D., E. Anichini, N. Pedersen, F. Blasi, G. Gibbi, M. Pucci, and M. Ruggiero. 1993. Urokinase-urokinase receptor interaction: non-mitogenic signal transduction in human epidermal cells. Biochem. Biophys. Res. Commun. 190:347-352.

17. Waltz, D.A., and H.A. Chapman. 1994. Reversible cellular adhesion to vitronectin linked to urokinase receptor occupancy. J. Biol. Chem. 269:1474614750

18. Wei, Y., D.A. Waltz, N. Rao, R.J. Drummond, S. Rosenberg, and H.A. Chapman. 1994. Identification of the urokinase receptor as an adhesion receptor for vitronectin. J. Biol. Chem. 269:32380-32388.

19. Wei, Y., M. Lukashev, D.I. Simon, S.C. Bodary, S. Rosenberg, M.V. Doyle, and H.A. Chapman. 1996. Regulation of integrin function by the urokinase receptor. Science (Wash. DC). 273:1551-1555.

20. Wang, N., E. Planus, M. Pouchelet, J.J. Fredberg, and G. BarlovatzMeimon. 1995. Urokinase receptor mediates mechanical force transfer across the cell surface. Am. J. Physiol. 268:C1062-C1066.

21. Declerck, P.J., M. De Mol, M.-C. Alessi, S. Baudner, E.-P. Paques, K.T. Preissner, G. Muller-Berghaus, and D. Collen. 1988. Purification and characterization of a plasminogen activator inhibitor 1 binding protein from human plasma: identification as a multimeric form of S protein (vitronectin). J. Biol. Chem. 263:15454-15461.

22. Seiffert, D., J. Mimuro, R.R. Schleef, and D.J. Loskutoff. 1990. Interactions between type 1 plasminogen activator inhibitor, extracellular matrix and vitronectin. Cell Differ. Dev. 32:287-292.

23. Singer, S.J., and A. Kupfer. 1986. The directed migration of eukaryotic cells. Annu. Rev. Cell Biol. 2:337-365.

24. Palecek, S.P., J.C. Loftus, M.H. Ginsberg, D.A. Lauffenburger, and A.F. Horwitz. 1996. Integrin-ligand binding properties govern cell migration speed through cell-substratum adhesiveness. Nature (Lond.). 385:537-540.

25. Cai, T.-Q., and S.D. Wright. 1995. Energetics of leukocyte integrin activation. J. Biol. Chem. 270:14358-14365.

26. Simon, D.I., N.K. Rao, H. Xu, Y. Wei, O. Majdic, E. Ronne, L. Kobzik, and H.A. Chapman. 1996. Mac-1 (CD11b/CD18) and the urokinase receptor (CD87) form a functional unit on monocytic cells. Blood. 88:3185-3194.

27. Niculescu, F., H.G. Rus, D. Porutiu, V. Ghiurca, and R. Vlaicu. 1989. Immunoelectron-microscopic localization of S-protein/vitronectin in human atherosclerotic wall. Atherosclerosis. 78:197-203.

28. Reilly, J.T., and J.R.G. Nash. 1988. Vitronectin (serum spreading factor): its localisation in normal and fibrotic tissue. J. Clin. Pathol. 41:1269-1272.

29. Deng, G., S.A. Curriden, S. Wang, S. Rosenberg, and D.J. Loskutoff. 1996. Is plasminogen activator inhibitor-1 the molecular switch that governs urokinase receptor-mediated cell adhesion and release? J. Cell Biol. 134:15631571.

30. Kanse, S.M., C. Kost, O.G. Wilhelm, P.A. Andreasen, and K.T. Preissner. 1996. The urokinase receptor is a major vitronectin-binding protein on endothelial cells. Exp. Cell Res. 224:344-353.

31. Simon, D.I., H. Xu, and D.E. Vaughn. 1995. Cathepsin D-like aspartyl protease activity mediates the degradation of tissue-type plasminogen activator/plasminogen activator inhibitor-1 complexes in human monocytes. Biochim.
Biophys. Acta. 1268:143-151.

32. Yatohgo, T., M. Izumi, H. Kashiwagi, and M. Hayashi. 1988. Novel purification of vitronectin from human plasma by heparin affinity chromatography. Cell Struct. Funct. 13:281-292.

33. Berkenpas, M.B., D.A. Lawrence, and D. Ginsburg. 1995. Molecular evolution of plasminogen activator inhibitor-1 functional stability. EMBO J. 14 2969-2977.

34. Sane, D.C., T.L. Moser, and C.S. Greenberg. 1991. Limited proteolysis of vitronectin by plasmin destroys heparin binding activity. Thromb. Haemosta sis. 66:310-314.

35. Suzuki, S., M.D. Pierschbacher, E.G. Hayman, K. Nguyen, Y. Ohgren, and E. Ruoslahti. 1984. Domain structure of vitronectin: alignment of active sites. J. Biol. Chem. 259:15307-15314.

36. Chain, D., T. Kreizman, H. Shapira, and S. Shaltiel. 1991. Plasmin cleavage of vitronectin: identification of the site and consequent attenuation in binding plasminogen activator inhibitor-1. FEBS Lett. 285:251-256.

37. Kost, C., W. Stuber, H.J. Ehrlich, H. Pannekoek, and K.T. Preissner. 1992. Mapping of binding sites for heparin, plasminogen activator inhibitor-1, and plasminogen to vitronectin's heparin-binding region reveals a novel vitronectin-dependent feedback mechanism for the control of plasmin formation. J. Biol. Chem. 267:12098-12105.

38. Gechtman, Z., R. Sharma, T. Kreizman, M. Fridkin, and S. Shaltiel. 1993. Synthetic peptides derived from the sequence around the plasmin cleavage site in vitronectin: use in mapping the PAI-1 binding site. FEBS Lett. 315: 293-297.

39. Kost, C., K. Benner, A. Stockmann, D. Linder, and K.T. Preissner. 1996. Limited plasmin proteolysis of vitronectin: characterization of the adhesion protein as morpho-regulatory and angiostatin-binding factor. Eur. J. Biochem. 236:682-688.

40. Andreasen, P.A., L. Sottrup-Jensen, L. Kjoller, A. Nykjaer, S.K. Moestrup, C.M. Petersen, and J. Gliemann. 1994. Receptor-mediated endocytosis of plasminogen activators and activator/inhibitor complexes. FEBS Lett. 338:239-245.

41. Meissauer, A., M.D. Kramer, V. Schirrmacher, and G. Brunner. 1992. Generation of cell surface-bound plasmin by cell-associated urokinase-type or secreted tissue-type plasminogen activator: a key event in melanoma cell invasiveness in vitro. Exp. Cell Res. 199:179-190.

42. Liu, G., M.A. Shuman, and R.L. Cohen. 1995. Co-expression of urokinase, urokinase receptor, and PAI-1 is necessary for optimum invasiveness of cultured lung cancer cells. Int. J. Cancer. 60:501-506.

43. Crowley, C.W., R.L. Cohen, B.K. Lucas, G. Liu, M.A. Shuman, and A.D. Levinson. 1993. Prevention of metastasis by inhibition of the urokinase receptor. Proc. Natl. Acad. Sci. USA. 90:5021-5025.

44. Kobayashi, H., J. Gotoh, M. Fujie, H. Shinohara, N. Moniwa, and T. Terao. 1994. Inhibition of metastasis of Lewis lung carcinoma by a synthetic peptide within growth factor-like domain of urokinase in the experimental and spontaneous metastasis model. Int. J. Cancer. 57:727-733.

45. Min, H.Y., L.V. Doyle, C.R. Vitt, C.L. Zandonella, J.R. Stratton-Thomas, M.A. Shuman, and S. Rosenberg. 1996. Urokinase receptor antagonists inhibit angiogenesis and primary tumor growth in syngeneic mice. Cancer Res. 56: $2428-2433$.

46. Seiffert, D., G. Ciambrone, N.V. Wagner, B.R. Binder, and D.J. Loskutoff. 1994. The somatomedin B domain of vitronectin: structural requirements for the binding and stabilization of active type 1 plasminogen activator inhibitor. J. Biol. Chem. 269:2659-2666.

47. Eitzman, D.T., R.D. McCoy, X. Zheng, W.P. Fay, T. Shen, D. Ginsburg, and R.H. Simon. 1996. Bleomycin-induced pulmonary fibrosis in transgenic mice that either lack or overexpress the murine plasminogen activator inhibitor-1 gene. J. Clin. Invest. 97:232-237.

48. Mueller, B.M., Y.B. Yu, and W.E. Laug. 1995. Overexpression of plasminogen activator inhibitor 2 in human melanoma cells inhibits spontaneous metastasis in scid/scid mice. Proc. Natl. Acad. Sci. USA. 92:205-209.

49. Soff, G.A., J. Sanderowitz, S. Gately, E. Verrusio, I. Weiss, S. Brem, and H.C. Kwaan. 1995. Expression of plasminogen activator inhibitor type 1 by human prostate carcinoma cells inhibits primary tumor growth, tumor-associated angiogenesis, and metastasis to lung and liver in an athymic mouse model. $J$. Clin. Invest. 96:2593-2600.

50. Quax, P.H.A., G.N.P. van Muijen, E.J.D. Weening-Verhoeff, L.R Lund, K. Dano, D.J. Ruiter, and J.H. Verheijen. 1991. Metastatic behavior of human melanoma cell lines in nude mice correlates with urokinase-type plasminogen activator, its type-1 inhibitor, and urokinase-mediated matrix degradation. J. Cell Biol. 115:191-199.

51. Padro, T., J.J. Emeis, M. Steins, K.W. Schmid, and J. Kienast. 1995 Quantification of plasminogen activators and their inhibitors in the aortic vesse wall in relation to the presence and severity of atherosclerotic disease. Arterioscler. Thromb. Vasc. Biol. 15:893-902.

52. Gladson, C.L., and D.A. Cheresh. 1991. Glioblastoma expression of vitronectin and the $\alpha \mathrm{v} \beta 3$ integrin: adhesion mechanism for transformed glial cells. J. Clin. Invest. 88:1924-1932.

53. Landau, B.J., H.C. Kwaan, E.N. Verrusio, and S.S. Brem. 1994. Elevated levels of urokinase-type plasminogen activator and plasminogen activator inhibitor type-1 in malignant human brain tumors. Cancer Res. 54:1105-1108. 
54. Sumiyoshi, K., K. Serizawa, T. Urano, Y. Takada, A. Takada, and S. Baba. 1992. Plasminogen activator system in human breast cancer. Int. J. Cancer. 50:345-348.

55. Jankun, J., H.W. Merrick, and P.J. Goldblatt. 1993. Expression and localization of elements of the plasminogen activation system in benign breast disease and breast cancers. J. Cell. Biochem. 53:135-144.

56. Sier, C.F.M., H.J.M. Vloedgraven, S. Ganesh, G. Griffioen, P.H.A. Quax, J.H. Verheijen, G. Dooijewaard, K. Welvaart, C.J.H. van de Velde, C.B.H.W. Lamers, and H.W. Verspaget. 1994. Inactive urokinase and increased levels of its inhibitor type 1 in colorectal cancer liver metastasis. Gastroenterology. 107:1449-1456.

57. Takeuchi, Y., A. Nakao, A. Harada, T. Nonami, T. Fukatsu, and H. Takagi. 1993. Expression of plasminogen activators and their inhibitors in human pancreatic carcinoma: immunohistochemical study. Am. J. Gastroenterol. 88:1928-1933.
58. Stefansson, S., and D.A. Lawrence. 1996. The serpin PAI-1 inhibits cell migration by blocking integrin $\alpha_{\mathrm{v}} \beta_{3}$ binding to vitronectin. Nature (Lond.). 383: 441-443.

59. Janicke, F., M. Schmitt, L. Pache, K. Ulm, N. Harbeck, H. Hofler, and H. Graeff. 1993. Urokinase (uPA) and its inhibitor PAI-1 are strong and independent prognostic factors in node-negative breast cancer. Breast Cancer Res. Treat. 24:195-208.

60. Grondahl-Hansen, J., I.J. Christensen, C. Rosenquist, N. Brunner, H.T. Mouridsen, K. Dano, and M. Blichert-Toft. 1993. High levels of urokinase-type plasminogen activator and its inhibitor PAI-1 in cytosolic extracts of breast carcinomas are associated with poor prognosis. Cancer Res. 53:2513-2521.

61. Pedersen, H., J. Grondahl-Hansen, D. Francis, K. Osterlind, H.H. Hansen, K. Dano, and N. Brunner. 1994. Urokinase and plasminogen activator inhibitor type 1 in pulmonary adenocarcinoma. Cancer Res. 54:120-123. 